\title{
DESIGN OF THE VIBROSTABILISATION STAND FOR REDUCING RESIDUAL STRESSES IN DISCS USED IN THE CONSTRUCTION OF MULTI-PLATE CLUTCHES AND BRAKES
}

\author{
Jerzy JAROSZEWICZ*, Krzysztof ŁUKASZEWICZ*, Vladimir ANTONYUK* \\ *Faculty of Engineering Management, Bialystok University of Technology, ul. Ojca Tarasiuka 2, 16-001 Kleosin, Poland \\ ${ }^{* *}$ Joint Institute of Mechanical Engineering of the NAS of Belarus, 12 Akademicheskaya Street, 220072, Minsk, Republic of Belarus \\ j.jaroszewicz@pb.edu.pl, k.lukaszewicz@pb.edu.pl, vladi@tut.by
}

received 17 March 2018, revised 12 March 2019, accepted 18 March 2019

\begin{abstract}
Heavy-duty, oil-cooled brake discs (MMOTs) are often used in heavy-duty brake systems manufactured by companies such as Caterpilar, Clark, Komatsu and Liebherr. These discs are usually made of special steels, and in most cases, the flatness of the working surfaces should not exceed $0.15-0.30 \mathrm{~mm}$. Although the technological processes of friction disc production include several stages of heat treatment and grinding, the required accuracy is not achieved in some cases. In addition, the remaining residual stresses lead to the deformation of the discs during their lifetime. In production practice, three methods are used to reduce residual stresses: thermo-fixing, dynamic stabilisation and vibratory stabilisation consisting in bringing discs to transverse resonance vibrations and maintaining resonance until significant stress reduction. The article proposes a method of stabilising the discs using the resonance phenomenon at the first few frequencies. In this article, Cauchy's function method and characteristic series method are used to develop solution value problem for clamped circular plates with discrete inclusions as concentrated masses and springs. Calculation methods for quick estimation of the own frequency of discs with additional ring mass enabling the use of low power vibration inductors are presented. The use of a special membrane and a pneumatic cushion in the construction of the stand allows to induce vibrations of higher frequencies.
\end{abstract}

Key words: Heavy Vehicles, Friction Discs, Multi-Disc Brake, Vibratory Stabilisation

\section{INTRODUCTION}

Brake and clutch discs have the form of thin rings sensitive to permanent deformations arising as a result of mechanical treatment and, above all, thermal treatment. In order to exclude undesirable phenomena resulting from the surface-heat treatment, various technological measures are applied, which, in most cases, consist in subjecting the elements to static loads. However, these treatments do not completely eliminate internal stresses and thus do not guarantee a stable element geometry for a longer period.

Residual stress is a stress existing and balancing within the material after cessation of interactions causing its formation. They arise practically with all technological processes of heat treatment, mechanical treatment, pressure treatment and many other types of machining. The causes of residual stress are diverse (heterogeneity of plastic deformation, non-uniformity of the temperature field and phase transformations). In real polycrystalline material, internal stresses can be divided into three types (Rossini et al., 2012; Salvati and Korsunsky, 2017):

- stresses type 1 - they balance themselves within the whole structure of a part (if such an element is cut into pieces, its parts will not match because of their deformation after the release of stresses);

- stresses type 2 (intercrystalline or interphase stresses) - they balance within the polycrystal, also known as structural stresses;

- stresses type 3 - arise inside the crystal, for example, around dislocations within crystals.

Regardless of the type of occurring stresses, their action al- ways causes elastic deformation of the crystal lattice. It can be noticed that internal stresses play a significant role in the process of deformation and initiation of microdamage (Almer et al., 2000; Meng et al., 2017; Mughrabi, 2013; Pedrosa et al., 2011; Sangid, 2013). It is believed that the direct cause of internal stresses in the polycrystalline body is the geometric incompatibility of the deformation caused by the anisotropy of the mechanical properties of individual crystals. In polycrystalline materials, this generates a heterogeneous state of plastic deformation. Plastic deformation running at finite speed causes an increase in the microdamage of the structure. Material, because of the distortion of the crystal lattice, becomes structurally unstable. Return to a more permanent state proceeds spontaneously. Internal stresses and distortion of the crystal lattice are interdependent. It is believed that in metallic materials, internal stresses are the result of elastic deformation of the crystal lattice. If favourable conditions occur, elastic defects of the structure relax and internal stresses disappear (Adamczyk, 1993; Wesołowski, 1981), relaxation of elastic defects of the structure causes a decrease in deformation strengthening and, in many cases, leads to irreversible deformation (Salvati and Korsunsky, 2017). At present, there are many experimental methods for determining residual stresses, classification of which can be found, for example, in Ghasri-Khouzani (2017), Hałas (2010), Khan and Gangele (2016), Schajer (2013), and Vourna et al. (2015). This work presents a proposal for methods to improve the geometrical parameters of brake friction discs, in particular flatness deviations by using a cyclic load with variable amplitude, thermo-fixing and vibration stabilisation, complementing the technological process of disc manufacture. The basis of first these methods is a proven theory (Antonyuk, 2004; Antonyuk et al., 
2016) that cyclic loading of elements, carried out under specific conditions, affects the stabilisation of mechanical properties and the effect of relaxation of residual stresses.

The aim of this work is to design the stand for effective reduction of residual stress, using the vibration method, in clutch discs and brakes of multi-plate heavy-duty vehicles.

\section{BRAKE DISCS TECHNOLOGICAL PROCESS}

In brake systems of modern heavy-duty vehicles used in open-cast mines, oil-cooled multi-disc brakes (MMOT) are applied with an outside diameter of up to $960 \mathrm{~mm}$. Table1 presents some parameters of friction discs of manufacturers of selected heavy goods vehicles (HGVs).

Table 1. Parameters of friction discs with inner toothed rims in wet multidisc brakes

\begin{tabular}{|c|c|c|c|}
\hline Manufacturers & Model & $\begin{array}{c}\text { External } \\
\text { diameter of } \\
\text { disc, } \mathbf{D}(\mathbf{m m})\end{array}$ & $\begin{array}{c}\text { Internal } \\
\text { diameter of } \\
\text { disc, } \mathbf{d} \text { (mm) }\end{array}$ \\
\hline Bielaz & 75570 & 885 & 652 \\
\hline Caterpillar & CAT 785 & 870 & 660 \\
\hline Clark & LCB 36200 & 625.6 & 480 \\
\hline Komatsu & HD 1600 & 960 & 660 \\
\hline Rockwell & $5-38856$ & 565 & 425 \\
\hline
\end{tabular}

Figure 1 shows an exemplary longitudinal section of a wet multi-disc brake used, inter alia, in Bielaz 75570 rigid dump truck. Schematic markings of damage observed during operation are given as follows: $A$, signs of spline deformation; $B$, damage during disassembly because of jamming; $C$, loss of shape stability; $D$, surface wear, annular grooves and indentations.

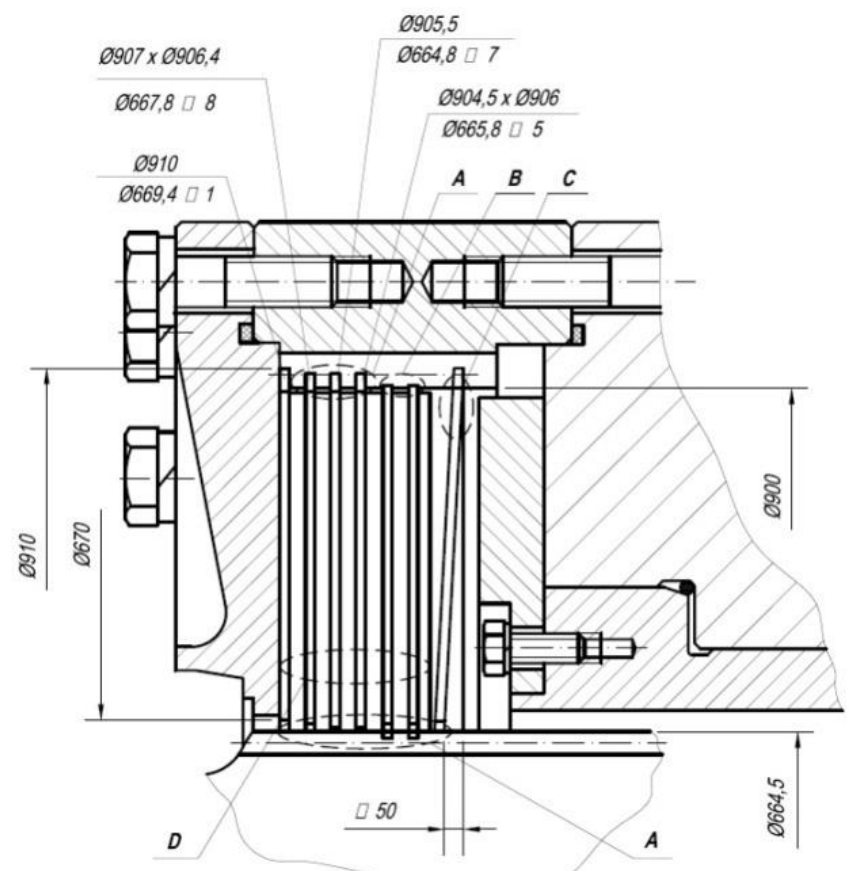

Fig. 1. Exemplary longitudinal section of a wet multi-disc brake in Bielaz 75570 rigid dump truck
The basic technological requirement for such discs is to obtain a minimal value of geometrical deviation of flatness of working surfaces. The technological process of making friction brake discs includes cutting of half-ring blanks, straightening, hardening with high tempering, rough grinding of working surfaces, cutting of gear rims, tempering with resistance up to 8 hours with package cooling and finishing grinding. Unfortunately, after the aforementioned operations, it is often not possible to maintain a proper flatness deviation of the working surfaces. The analysis of foreign technologies in the production of discs shows that specialist companies such as Miba and Hoerbiger are capable of manufacturing discs with a diameter of not more than $600 \mathrm{~mm}$ and with an accuracy of flatness deviation of $0.4 \mathrm{~mm}$ (Antonyuk, 2004).

A typical technological process for disc manufacturing consists of the following steps (Antonyuk et al., 2017):

- cutting from sheets using press or oxygen-laser cutting;

- thermal straightening using a press and an electrofusion furnace in packages of $80-120$ units at $650^{\circ} \mathrm{C}$ within $6 \mathrm{~h}$, with the subsequent cooling of the package in the air;

- turning of working surfaces;

- high-frequency induction hardening to 30-36 Rockwell hardness or hardening and tempering, which is carried out by heating the freely hanging discs in an electric furnace of up to $850^{\circ} \mathrm{C}$ for $2 \mathrm{~h}$ with subsequent cooling in oil, high tempering is carried out in packages of 70 pieces while heating in the furnace to $575^{\circ} \mathrm{C}$ for $4-5 \mathrm{~h}$ with the final cooling in the air;

- initial grinding of working surfaces using a surface grinder;

- turning of external and internal diameter;

- cutting teeth or external/internal splines using a gear hobber;

- thermal resistance in a $40-50$ package at $450^{\circ} \mathrm{C}$ for $5 \mathrm{~h}$, followed by cooling in air;

- finish grinding of working surfaces;

- manual straightening on the plate;

- degaussing.

Despite the use of a large-range technological process, often the required flat surface tolerance is not achieved in the finished product.

Figure 2 presents a graph showing the percentage share of elements with the assumed tolerance at individual stages of production.

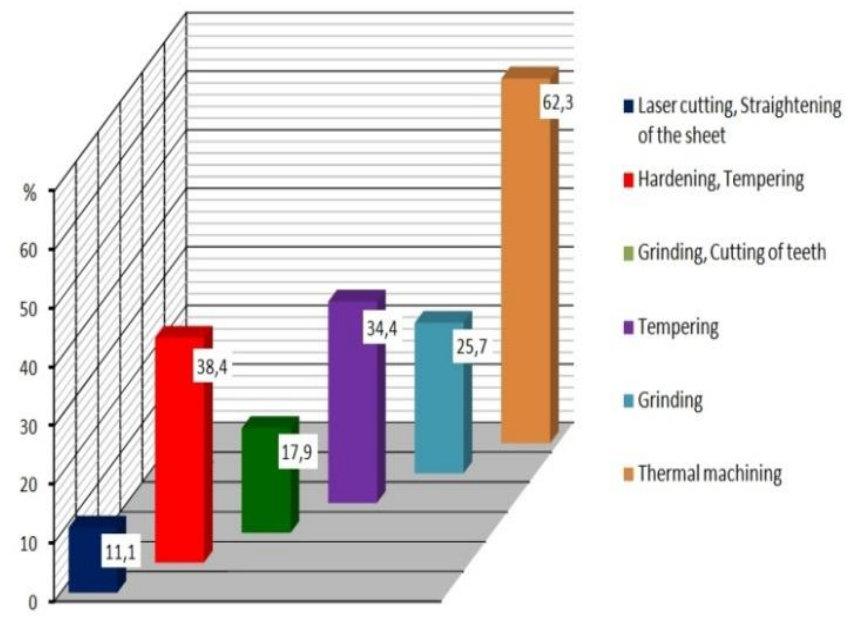

Fig. 2. Percentage share of elements with the assumed tolerance at individual stages of production of discs for BELAZ 7555B 
On the basis of the analysis of the impact of individual operations on the deviation of the disc made of 30HGSA steel, with $\varnothing 507 \mathrm{~mm}$ toothed rim, ø449 $\mathrm{mm}$ inner hole, $4 \mathrm{~mm}$ thickness and final of 269-321 Brinell hardness, the following conclusions were made:

- a significant deviation from the flatness appears at the beginning of the technological process in the operation of cutting out of the blank;

- after hardening and high tempering, internal stresses arise, which cause significant elastic deformation of the discs.

As a result of the presented operations, the sum of the mean strain and the deviation from the plane is not in the acceptable range. In order to remove non-flatness, a number of vibration and thermal methods can be used, but the most effective method has turned out to be the cyclic deformation using the appropriate tooling (Antonyuk et al., 2016).

\section{PROPOSED METHODS FOR REDUCING RESIDUAL STRESSES}

It can be concluded that the problem of reducing the level of residual stresses is very difficult. When exerting external loads in the process of machining or operation, residual stresses, adding up to stresses from external forces, may exceed the elastic limit, leading to uneven plastic deformation, warping, twisting and so on. Moreover, a significant reduction in counteracting the loss of the element's stability may also occur. The technological cycle of making a part with low stiffness includes many operations: straightening; thermal machining, often repeated multiple times; and machining. Each of these operations contributes its residual stresses, which cause deformations of parts both at the production stage and during their operation. Whilst straightening of nonheat treated rigid elements, such as some shafts, is relatively easy, straightening the flaccid discs is a problem.

\subsection{Dynamic stabilisation}

One of the most effective methods of reducing residual stresses, confirmed in manufacturing practice is the dynamic stabilisation involving bilateral bending of the disc at a specific amplitude and number of cycles (Antonyuk, 2004). In order to achieve the appropriate stabilisation effects, it is necessary to properly control the process by taking into account material properties, including the size of the cyclic deformation hysteresis loop. For the dynamic stabilisation realisation, it is needed to create elastoplastic deformations and stresses that lead to the occurrence of a loop of a hysteresis in the details' material.

The researches of materials' properties in this zone mark the positive influence of cyclic loading on the decrease in residual pressure and material hardening (Chukkan et al., 2018, Kwofie, 2011, Wang et al., 2017).

The dynamic stabilisation operation can be carried out in a special station, the principle of which is described in the works (Antonyuk, 2004). Figure 3 shows the schematic diagram of the station constructed for the needs of the Bielaz Mining Trucks manufacturer in Minsk, Belarus.

The dynamic stabilisation of friction discs consists in placing a work piece between radially bearing-supported conical upper rollers and similar lower rollers. The upper rollers are able to move vertically and load the disc with a specific transverse force. The disc is rotated through the lower rollers, which are driven by radially spaced electric motors. As a result, bilateral bending of the discs is obtained with a specific transverse force and deflection.

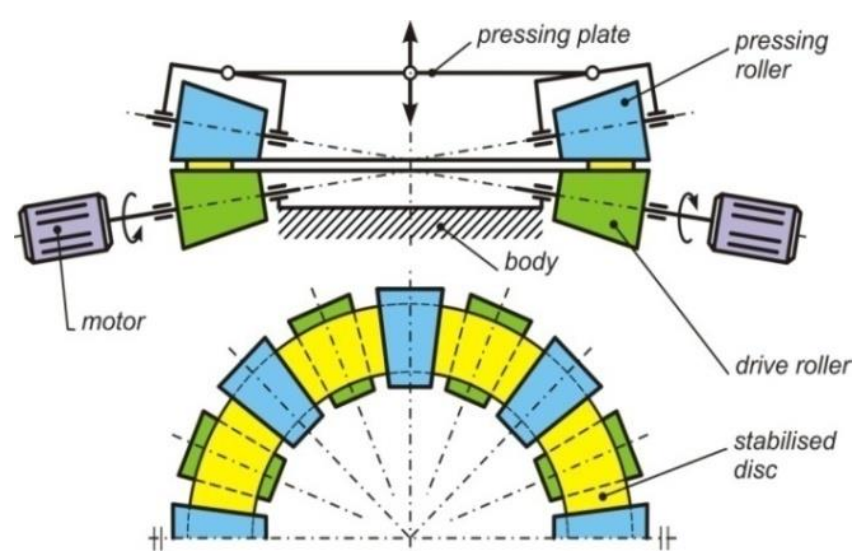

Fig. 3. Schematic diagram of the station for the dynamic stabilisation of friction discs

\subsection{Thermal machining (thermo-fixing)}

Common methods of reducing residual stresses include various types of heat treatment: tempering, low temperature annealing and natural ageing. The basic mechanism for changing the residual stresses is their relaxation, which proceeds more intensively at raised temperature (Zijlstra et al., 2016). In heat treatment, aimed at reducing residual stresses, the product may, however, undergo 'bending' deformations. A large change in the temperature in the product with residual stresses not only can change the dimensions and shape of the product, but also the product may undergo destruction, especially tensile stresses are dangerous in this case (Świć, 2009). Residual stresses often reduce the strength of products at variable and cyclic loads and affect the wear at sliding friction or rolling friction.

The following have been noticed during the heat treatment process:

- residual stresses are not eliminated completely, which is conditioned by the temperature of tempering, the time of heating, the material and the mass of the product;

- during heating and then cooling, the semi-finished product changes its shape and dimensions;

- tempering is a labour-intensive operation that reduces the process efficiency.

There have been attempts to solve the problem of residual stresses in heat treatment - for example, by introducing a new operation, thermal stabilisation - using special process control systems (Świć, 2009).

The thermo-fixing method, in reference to flat elements such as a plate or a disc, is used in production practice in such a way that the details are placed in a press with a heated die in packets (e.g. 10 pieces each). After a certain time, the packets are cooled slowly under load.

\subsection{Vibratory stabilisation}

In vibratory machining, yet another processes used in this case, vibration energy penetrates into the metal and, as a result, into the polycrystalline material and crystal displacement takes 
place, which is accompanied by a change in the distribution of stresses (Vardanjani et al., 2016 ). It has been pointed out (Khan and Gangele, 2016; Świć, 2009) that oscillations should occur at a resonant frequency or close to it. The vibration method is suitable for lowering the level of residual stresses obtained by plastic deformation methods in semi-finished products and those generated during mechanical machining.

Another interesting method from a practical point of view involves short-term, swing deformation of a given element. This method is characterised by low energy consumption, simplicity and economy.

Vibration annealing can be applied at any stage of the technological process, for example, during roughing or before finishing, mainly eliminating stresses caused by plastic working of the semifinished product (Adamski, 2015).

The vibrostabilisation method is used for a wide variety of structural components, including friction discs for brakes and clutches. In the work by Gupalov and Zakuraev (2011), the construction of the stand for the stabilisation of geometrical parameters and the algorithm for controlling the process of lowering the values of flatness deviations of friction discs are presented. Figure 4 shows a diagram of the stand for straightening the discs. The process of disc straightening consists of two stages. Stage 1 includes measurements of the disc and identification of the areas with the highest convexity value. Then a suitable force is applied in these places. During stage 2, vibrations in the frequency range of $50-150 \%$ of the disc's own frequency are applied to the static load.

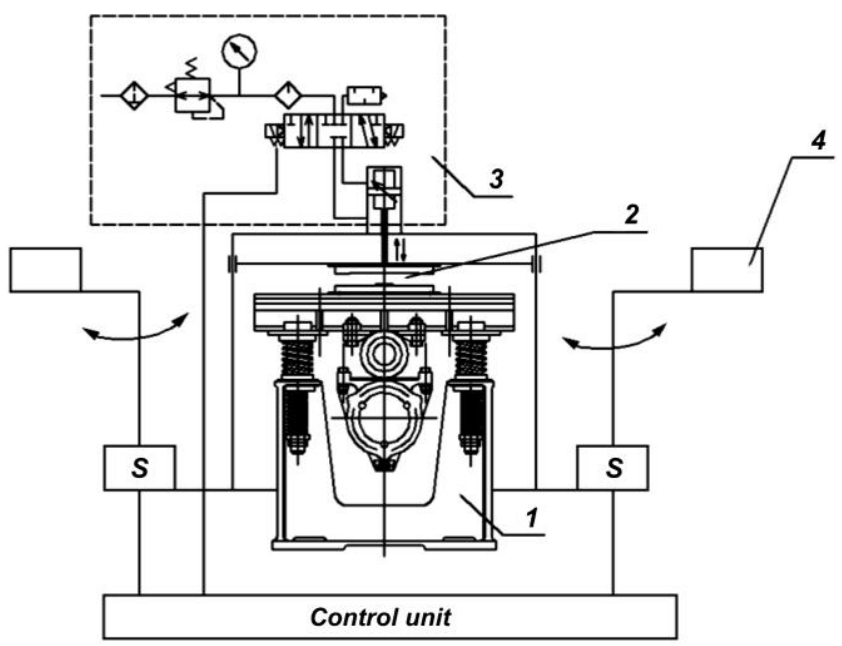

Fig. 4. Schematic diagram of the station for vibrostabilisation of discs (Gupalov and Zakuraev, 2011): 1, vibration inducer and support bracket; 2, work zone; 3, pneumatic system with an actuator; 4, load-relief system; $\mathrm{S}$, damping element

Experiments carried out at the stand (Fig. 4) showed the highest reduction of flatness deviation with a disc deflection of 2-3 $\mathrm{mm}$, a frequency of $50 \mathrm{~Hz}$, a vibration amplitude of $0.32 \mathrm{~mm}$ and an exposure time of $3 \mathrm{~min}$. The study by Gupalov (2013) presents a number of research results using this method, including measurements of microhardness of disc material. Gupalov proved that the vibratory stabilisation technology being introduced at machinebuilding enterprises will improve the quality and reliability of machinery as a whole.

The distinguishing feature of the method presented in the works by Gupalov and Zakuraev (2011) and Gupalov (2013) is the fact that preliminary measurements of the values and type of flatness deviations allow to impact directly on the curved areas of the disc and to create conditions for relaxation of residual stresses with a minimum level of input energy.

\section{A CONCEPTUAL DESIGN OF A STAND FOR VIBRATORY STABILISATION OF DISCS}

The method of vibratory stabilisation, presented in this article, is an original proposition of the author and bears the hallmark of innovation in this field. Often, the considerations in the literature are limited to the vibration stabilisation of shafts, welded structures and cast structures. What can be observed is the lack of sufficient data on the brake discs. The presented method requires experimental verification. The friction disc has the shape of a ring with a spline notched on the outer circumference and a smooth hole in its centre. It is proposed to stabilise the full disc with a ring load attached to the surface on the radius of the inner hole. Placing an additional load of about $10 \%$ load of the plate is used to reduce the natural frequency and efficiently resonance to bring the target material into accelerated ageing and obtain a flatness deviation of $<0.2 \mathrm{~mm}$.

Schemes of the proposed solution for the stand and measurement systems are given in Figs. 5 and 6.

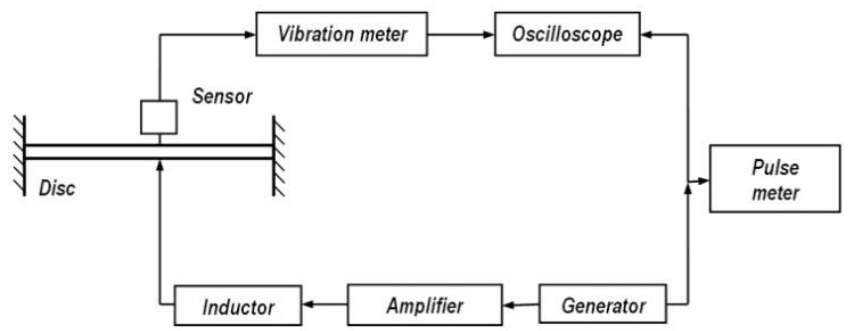

Fig. 5. Schematic drawing of a stand for vibratory stabilisation of discs by resonance

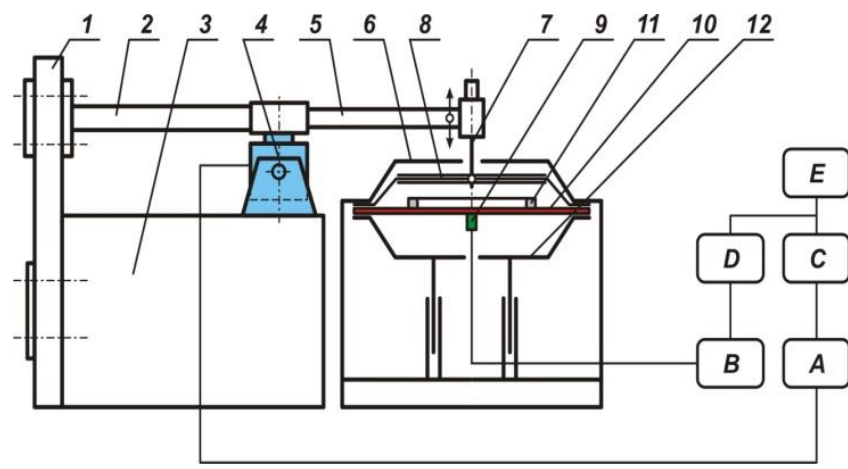

Fig. 6. Schematic diagram of a device for reducing residual stress in discs by vibration: 1 , support bracket; 2 , beam; 3 , body; 4 , vibration inducer; 5 , slide bar; 6 , upper lid; 7 , dowel pin; 8, membrane; 9, vibration sensor; 10, disc; 11, additional load; 12 , moving table; A, amplifier; B, load amplifier; C, vibration generator; D, oscilloscope; E, control unit

The disc (10) subjected to vibratory stabilisation is placed on the scissor lift table (12). Then the table (12) travels upwards, for example, using a screw mechanism or hydraulic actuators, pressing the disc to the top cover (6). As a result, the rigid edge clamping is obtained. There is a flexible membrane (8) between the top 
cover (6) and the plate, thanks to the vibrations of the plate initiated by the movement of air enclosed in airtight space between the plate and the membrane. The movement of the membrane is caused by a pin (7) connected to the moving arm (5).

The vibration excitation system consists of control system $E$, generator $C$, amplifier $A$ and vibration inducer (4). The active part of the vibration inducer is connected to the beam 2, whose end is rigidly attached to the support bracket 1 . The beam is made of a steel tube. The vibrations of the electromagnetic actuator initiate the flexural vibrations of the beam 2 . At the end of the beam, a sliding arm (5) is fixed in the form of a tube made of an aluminium alloy, which is connected to the dowel pin (7) of the membrane (8). In this way, the vibrations of the beam are transferred to the membrane. The vibrations of the disc (10) are processed by the sensor (9) and the charge amplifier B into an electrical signal that is then fed into the oscilloscope D. The oscilloscope is simultaneously fed with the voltage from the generator $C$. Because the frequencies of both runs are same, the oscilloscope screen displays an ellipse. Changing the frequency of the generator causes a change in the frequency of forced oscillations of the inductordisc system. At the moment of equating the frequency of forced vibrations with the natural frequency of the plate, a resonance phenomenon arises. It is manifested by a rapid increase in the vibration amplitude of the plate. Then the largest amplitude is observed on the oscilloscope screen. By slowly changing the frequency of the generator in the resonance zone, the phase shift between the applied force and the vibrating beam changes. At resonance, the shift is $90^{\circ}$, which is equivalent to the vertical position of ellipse on the oscilloscope screen. Thus, when going through resonance, the 'rotation' of the ellipse occurs. After accurately capturing the resonance moment, the plate's natural frequency is read using the graphic interface of the control system $\mathrm{E}$. For the discussed system, the search for these frequencies takes place by manually tuning the frequency of the generator to the disc's natural frequencies.

It is proposed to use an inductor model S062 with the frequency range of up to $200 \mathrm{~Hz}$ and an amplitude of $1 \mathrm{~mm}$. Magnetic vibration inducers dramatically reduce the impact force as the excitation frequency increases above $200 \mathrm{~Hz}$ (Uhl and Panuszka, 1983), as inductive resistance increases. Therefore, in Sections 5 and 6 , an analytical and numerical method is proposed for choosing the size of the additional secondary ring, taking into account its radius.

\section{ANALYTICAL DETERMINATION OF NATURAL FREQUENCY IN BRAKE DISCS}

In order to precisely determine the frequency of generated pulses and selection of the vibration inducer, analytical calculations of the natural frequency were carried out depending on the size of the disc, its fixing and the radius of the additional mass. Figure 7 presents disc models used for further calculations.

Study of the boundary problem of axisymmetric vibrations of the disc with discrete intercalations, whose distribution depends on the radial variable, is about solving the boundary problem described by equation (1) (Jaroszewicz and Zoryj, 2005):

$$
\begin{aligned}
& L_{0}[u]+r \chi u-\sum_{i=1}^{k} \alpha_{i} u\left(r_{i}\right) \delta\left(r-r_{i}\right)=0, \\
& 0<r_{1}<r_{2}<\cdots<r_{k}<R .
\end{aligned}
$$

Differential operator in equation (1) is in the following form:

$$
\begin{aligned}
L_{0}[u] & =u^{I V}+\frac{2}{r} u^{I I I}-\frac{1}{r^{2}}\left(1+2 n^{2}\right) u^{I I}+\frac{1}{r^{3}}\left(1+2 n^{2}\right) u^{I}- \\
& -\frac{1}{r^{4}}\left(1+2 n^{2}\right) u,
\end{aligned}
$$

where $u=u(r)$ is the bending amplitude, $\delta(r)$ is the Dirac delta function, $\alpha_{i}=\frac{1}{D}\left(m_{i} \omega^{2}-c_{i}\right)$ and $\chi=\frac{1}{D}\left(\varrho h \omega^{2}-b \omega-\right.$ $\left.\kappa^{2}\right)$.

a)

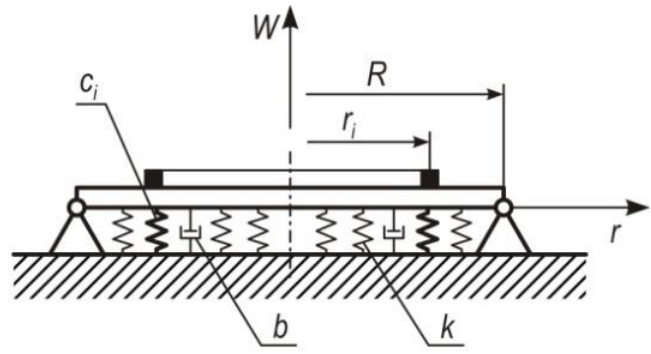

b)

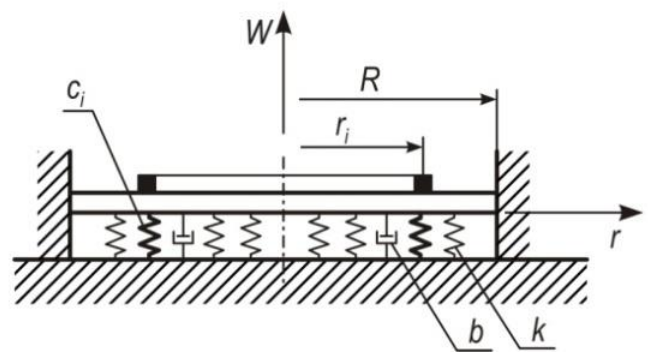

Fig. 7. Discs used in the analysis: (a) a disc pivotally supported at the edge and (b) a disc clamped at the edge

In equation (1) and expression (2) and in Fig. 7, the following parameters of intercalations in the form of point mass $m_{i}$ and elastic supports with rigidity $c_{i}$ are distributed on radii $r_{i}: D$ is the cylindrical rigidity, $\omega$ is the frequency parameter, $\varrho h$ is the volumetric mass density, $\chi$ is the elastic foundation coefficient and $n$ is the mode of vibrations.

Cylindrical stiffness of the disc can be defined using the following formula:

$D=\frac{E h^{3}}{12\left(1-v^{2}\right)}$.

In this article, two types of fixing the edges of the disc are considered: clamped and freely supported on the edge (Fig. 7):

$u(R)=0, u^{\prime}(R)=0$,

$u(R)=0, u^{\prime \prime}(R)+v R^{-1} u^{\prime}=0$.

Assuming that a massless disc is homogeneous, its edge is clamped and focusing on axisymmetric oscillations, the solution of the auxiliary problem limited in zero (equation 1) is in the following form (Roberson, 1951):

$u(r)=c_{0}+c_{1} r^{2}-F_{j} K_{0}\left(r, r_{j}\right) \Theta\left(r-r_{j}\right)$,

where $c_{0}, c_{1}$ are constants of integration, $K_{0}\left(r, r_{j}\right)$ is the basic function of operator $L_{0}[u]$ where $\alpha=r_{j}$ and $\Theta(r)$ is the Heaviside function.

The value of $F_{j}$ characterises a flex real forces concentrated on a circle with radius $r_{j}\left(r_{j} \geq r_{i}\right)$. From equation (5), we obtain 
$u^{\prime}(r)=c_{1} r-F_{j} K_{o}^{\prime}\left(r, r_{j}\right) \theta\left(r-r_{j}\right)$

By substituting equations (5) and (6) into condition (3), integration constants $c_{o}, c_{1}$ were determined, and on the basis of equation (6), impact coefficients $\beta_{i j}$ were determined:

$\beta_{i j}=u_{j}\left(r_{i}\right)=\frac{1}{2 R}\left[\left(R^{2}-r_{j}^{2}\right) K_{R i}^{\prime}-2 R K_{R i}\right]$.

In the case of $i=j=1$ in equation (7), the natural frequency $\omega$ of a mass less plate carrying point mass $M$ on a circle with a radius $r=r_{1}$ was determined:

$\frac{\omega^{2}}{D}=\frac{1}{\widetilde{\varrho} \beta_{11}} M=2 \pi r_{1} \tilde{\varrho}$,

where $\tilde{\varrho}$ is the linear density of mass rib and $D$ is the cylindrical stiffness.

Impact coefficient $\beta_{11}$ will eventually take the form of

$\beta_{11}=\frac{r_{1}}{2 R}\left(\frac{1}{4} R^{3}-\frac{1}{4} \frac{r_{1}^{4}}{R}-r_{1}^{2} R \ln \frac{R}{r_{1}}\right)$

By analogy, vibration frequencies corresponding to the first non-axisymmetric form can be determined. In the case of a freely supported plate, by taking into account the boundary conditions (4), the transformation should be carried out in the same way and finally obtained in the following form:

$\beta_{11}=\frac{r_{1}}{2(1+v)}\left[\frac{3}{4} R^{2}-r_{1}^{2}\left(1-\ln \frac{R}{r_{1}}\right)+v \frac{1}{4} R^{2}-r_{1} \ln \frac{R}{r_{1}}\right]$.

On the basis of equations (9) and (10), considering equation (8) and pointing $r_{1}$ to 0 , we get a much simpler pattern for the square of the basic frequency for cases when the mass $M$ significantly exceeds the unladen weight of the plate and is focused at the centre of symmetry $(r=0)$ (Jaroszewicz and Zoryj, 2005):

$\omega^{2}=\frac{16 \pi D}{M R^{2}}, \omega^{2}=\frac{16 \pi D(1+v)}{M R^{2}(3+v)}$

On the basis of equation (8), basic frequencies $\omega$ can be calculated by introducing frequency parameter $\gamma(x)$, which becomes dependant on the relation $x=\frac{r_{1}}{R}$. On the basis of equations (9) and (10), the following can be expressed:

$\omega=\gamma(x) \frac{1}{R^{2}} \sqrt{\frac{D}{\varrho h}}$.

For a clamped disc,

$[\gamma(x)]^{2}=\frac{16 \pi}{1-x^{4}+4 x^{2} \ln x}$.

For a freely supported disc,

$[\gamma(x)]^{2}=\frac{16 \pi(1+v)}{\left[3-x^{2}(1+\ln x)+v+4 x^{2} \ln x\right]}$.

Fig. 8 shows a graph of waveform in the frequency parameter depending on the radius of distribution of the additional mass and the method of supporting the disc.

To calculate the frequency in rad/s, formulas (12), (13) and (14) should be used, in which the following data are adopted: $R=$ $0.45 \mathrm{~m}, h=0.003 \mathrm{~m}$ and $D=620 \mathrm{Nm}$. The ring mass is distributed over a radius of $r_{1}=0.3 \mathrm{~m}$. Its value is $10 \%$ of the disc's own weight, with $m_{1}=0.94 \mathrm{~kg}$. Assuming $r_{1}$ and $m_{1}$, the crosssectional dimensions of the ring are determined and the natural frequencies are calculated:
- for clamped disc $-\omega=60 \mathrm{rad} / \mathrm{s}$,

- for freely supported disc $-\omega=35.4 \mathrm{rad} / \mathrm{s}$.

Bernstein-Kieropian tables can be used to calculate the higher frequencies of discs (Bernstein and Kieropian, 1960).

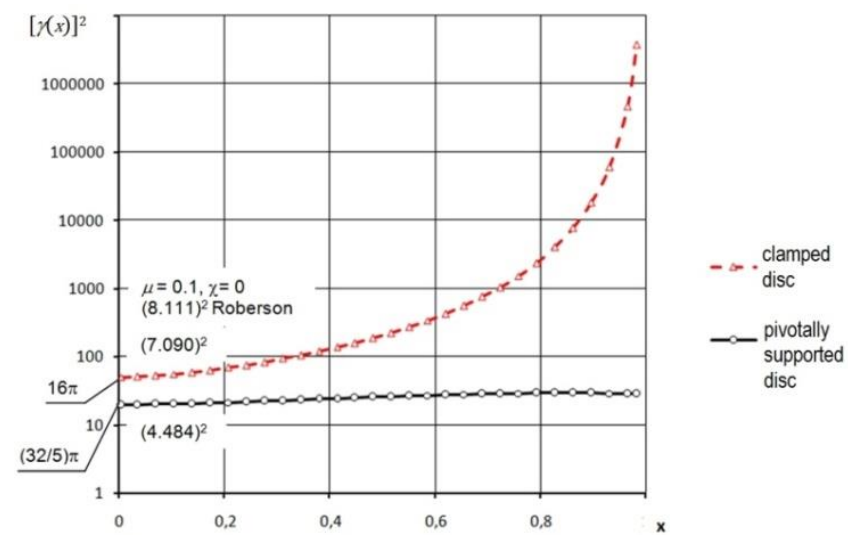

Fig. 8. The dependence of the basic frequency parameter $\gamma$ on the radius of distribution of the additional mass $x=\frac{r_{1}}{R}$ for the clamped disc and the pivotally supported disc

The inductor proposed in this work fully meets the demand. The use of higher additional weight $m_{1}$ results in a reduction of its own frequency. The frequency parameter values $\gamma(x)$ can also be read from the graph presented in Fig. 8.

\section{RESULTS OF ANALYTICAL AND NUMERICAL CALCULATIONS}

For comparison purpose, calculations of natural frequency of discs were made using the analytical relationships presented in Section 5 and the finite element method (FEM). The Autodesk Inventor software package equipped with the NASTRAN module was used. The comparison concerned only the first value of natural frequency of discs, with an additional mass $\left(m_{a}\right)$ determined analytically using the relations (11) and (12) and discs without additional mass. The focus was on calculations of modal analysis with linear material behaviour. Calculations are conducted for five vehicle discs mentioned in Table 1. The dimensions of discs, material constants and boundary conditions were adopted as in analytical studies. Owing to the uncomplicated shape of the disc, the problem was modelled as spatial, adopting a standard grid using parabolic tetrahedral elements. Table 2 presents information on the parameters of the generated grid for the target disc.

Table 2. Mesh parameters

\begin{tabular}{|c|c|}
\hline Type mesh & Parabolic tetrahedral \\
\hline Maximum element growth rate & 1.5 \\
\hline Refinement ratio & 0.2 \\
\hline Minimum/maximum triangle angle & $20 / 30^{\circ}$ \\
\hline Upper Jacobian ratio bound & 16 points \\
\hline Size & $12 \mathrm{~mm}$ \\
\hline Tolerance & $0.0356 \mathrm{~mm}$ \\
\hline Quality & High \\
\hline
\end{tabular}


The results of analytical and numerical calculations are presented in Table 3. The calculation of the percentage difference of results for individual types of discs and calculation methods was made according to formula (15):
$\Delta s=\left|\frac{\omega^{\mathrm{ANL}}-\omega^{\mathrm{FEM}}}{\omega^{\mathrm{ANL}}}\right| \cdot 100 \%$,

where, $\omega^{\mathrm{ANL}}$ is the natural frequency determined analytically and $\omega^{\mathrm{FEM}}$ is the natural frequency determined by FEM.

Table 3. Results of the comparison for a disc clamped at its outer radius

\begin{tabular}{|c|c|c|c|c|c|c|c|c|c|c|}
\hline Vehicle model & \multicolumn{2}{|c|}{75570} & \multicolumn{2}{|c|}{ CAT 785} & \multicolumn{2}{|c|}{ LCB 36200} & \multicolumn{2}{|c|}{ HD 1600} & \multicolumn{2}{|c|}{$5-38856$} \\
\hline$r_{l} / R$ & \multicolumn{2}{|c|}{0.74} & \multicolumn{2}{|c|}{0.76} & \multicolumn{2}{|c|}{0.76} & \multicolumn{2}{|c|}{0.67} & \multicolumn{2}{|c|}{0.75} \\
\hline \multirow{2}{*}{$\begin{array}{l}\text { First natural frequency of a } \\
\text { disc }\end{array}$} & $\omega^{\mathrm{ANL}}$ & $\omega^{\mathrm{FEM}}$ & $\omega^{\mathrm{ANL}}$ & $\omega^{\mathrm{FEM}}$ & $\omega^{\mathrm{ANL}}$ & $\omega^{\mathrm{FEM}}$ & $\omega^{\mathrm{ANL}}$ & $\omega^{\mathrm{FEM}}$ & $\omega^{\mathrm{ANL}}$ & $\omega^{\mathrm{FEM}}$ \\
\hline & \multicolumn{10}{|c|}{$(\mathrm{rad} / \mathrm{s})$} \\
\hline $\begin{array}{l}\text { Without additional load } \\
\qquad \mu=m_{d} / M=0\end{array}$ & 249.4 & 244.4 & 258.1 & 253.2 & 499.2 & 489.7 & 211.9 & 207.7 & 611.9 & 600.1 \\
\hline$\Delta s(\%)$ & \multicolumn{2}{|c|}{2.0} & \multicolumn{2}{|c|}{1.9} & \multicolumn{2}{|c|}{1.9} & \multicolumn{2}{|c|}{2.0} & \multicolumn{2}{|c|}{1.9} \\
\hline $\begin{array}{l}\text { With additional load } \\
\qquad \mu=m_{d} / M=0,1\end{array}$ & 830.3 & 398.9 & 975.2 & 341.6 & $1,966.1$ & 828.9 & 555.8 & 312.9 & 2202.7 & 822.1 \\
\hline$\Delta s(\%)$ & \multicolumn{2}{|c|}{51.9} & \multicolumn{2}{|c|}{64.9} & \multicolumn{2}{|c|}{57.8} & \multicolumn{2}{|c|}{43.7} & \multicolumn{2}{|c|}{62.7} \\
\hline
\end{tabular}

\section{DISCUSSION OF RESEARCH RESULTS}

Figure 7 and Table 3 show that the analytical frequency calculations obtained by the simplified Cauchy function without taking into account the weight of the plate and additional load lead to small differences $(2 \%)$ in relation to numerical calculations and very significant differences (43-65\%) with additional load distributed over radius $x$. The reason for this is the omission of the weight of the disc in the analytical method. The numerical model includes, in addition to load, an additional load-rib with stiffness discrete inclusion into continuous stiffness. Consideration of stiffness and load-rib in analytical terms is very difficult. In addition, attention should be paid to the fact that the ring load spread over radius $x$ increases the frequency (according to the graph in Fig. 7) as opposed to Roberson's calculations (Roberson, 1951), where the point load (Table 4) placed at the centre of the disc's symmetry reduces it.

Table 4. Base frequency parameter $\gamma$ in relation to additional load $\mu$

\begin{tabular}{|c|c|c|c|}
\hline $\boldsymbol{\mu}$ & 0 & 0.05 & 0.1 \\
\hline $\boldsymbol{\gamma}$ & 10.214 & 9.012 & 8.111 \\
\hline
\end{tabular}

The proposed analytical methods using the Cauchy function and FEM obtain results convergent to the experiment described in Section 9.5 of a monograph by Jaroszewicz and Zoryj (2005).

\section{CONCLUSION}

The engineering method of selection and calculation of loading modes is developed for purposeful use of dynamic stabilisation. The introduced technique has been probe tested and implemented for developing the technological concept and for creation of installation with digital programme control for dynamic stabilisa- tion of frictional brake discs of dump trucks.

The method of selection and calculation of control charts can be used for the dynamic stabilisation realisation in order to increase the accuracy and working capacity of details of clutch plate type, frictional discs, crankshafts, torque rods, pipes, sleeves and some other non-rigid details.

The device proposed at this work is characterised by the use of a pneumatic cushion, thanks to the possibility of inducing vibrations of higher rows.

Vibratory stabilisation is a more universal method than dynamic stabilisation; it can be applied to various objects, often with a complicated shape. In order to correctly perform the vibratory stabilisation process, it is advisable to carry out preliminary analytical or numerical calculations of the basic frequency estimation of the object.

\section{REFERENCES}

1. Adamczyk J. (1993), Theoretical metallurgy. Plastic deformation, strengthening and cracking, 3, Publisher of the Silesian University of Technology, Gliwice (in Polish).

2. Adamski W. (2015), Impact of Modern Manufacturing Technologies at Aircraft Design, Mechanik, nr 12, 1-5 (in Polish).

3. Almer J.D., Cohen J.B., Moran B. (2000), The effects of residual macrostresses and microstresses on fatigue crack initiation, Materials Science and Engineering, A284, 268-279.

4. Antonyuk V. (2004), Dynamic stabilisation of geometrical parametres of details with alternating, UP "Technoprint" Minsk.

5. Antonyuk V., Jaroszewicz J., Radziszewski L., Dragun Ł. (2016), Theoretical stress analysis-based improvement of friction clutch disc manufacturing process, Czasopismo Techniczne. Mechanika, Politechnika Krakowska, 113(4-M), 73-79.

6. Antonyuk V., Sandomirskij S., Jaroszewicz J. (2017), Testing the possibility of estimation of residual stress based on gradient of magnetic field, Przegląd Mechaniczny, 2, 9-13 (in Polish).

7. Bernstein, S.A., Kieropian, K.K. (1960), Calculation of frequency of bar systems by means of spectral function, Goststrojtechizdat, 281, Moscow (in Russian). 
8. Chukkan J.R, Wu G., Fitzpatrick M.E., Eren E., Zhang X., Kelleher J. (2018), Residual stress redistribution during elastic shake down in welded plates, MATEC Web of Conferences, FATIGUE 2018, 165, 21004, 1-6.

9. Ghasri-Khouzani M., Pengb H., Roggec R., Attardod R., Ostiguyd P., Neidige J., Billof R., Hoelzleg D., Shankara M.R. (2017), Experimental measurement of residual stress and distortion in additively manufactured stainless steel components with various dimensions, Materials Science \& Engineering, A707, 689-700.

10. Gupalov B.A. (2013), Technology and equipment for friction disk vibratory dressing, Wiestnik IrGTU, 9(80), 57-63 (in Russian).

11. Gupalov B.A., Zakuraev W.W. (2011), Kinetics of geometric parameters changes of friction discs during vibratory processing, Wiestnik Nauki Sibri, 1(1), 682-685 (in Russian).

12. Hałas W. (2010), Study of the influence of residual stresses on the accuracy of shaft production. Dissertation, Publisher of the Lublin University of Technology, Lublin (in Polish).

13. Jaroszewicz J., Zoryj L. (2005), Methods for analyzing axisymmetric oscillations of circular plates using the Cauchy influence function method, Rozprawy Naukowe Politechniki Białostockiej, 124, Białystok.

14. Khan N., Gangele A. (2016), Residual Stress Measurement Techniques: A Review, International Journal of Research in Engineering and Applied Sciences, 6(4), 151-157.

15. Kwofie S. (2011), Description and simulation of cyclic stress-strain response during residual stress relaxation under cyclic load, Procedia Engineering, 10, 293-298.

16. Meng L., Atli M., He N. (2017), Measurement of equivalent residual stresses generated by milling andcorresponding deformation prediction, Precision Engineering, 50, 160-170.

17. Mughrabi H. (2013), Microstructural fatigue mechanisms: Cyclic slip irreversibility, crack initiation, non-linear elastic damage analysis, International Journal of Fatigue, 57, 2-8.

18. Pedrosa P.D., Rebello J.M.A., Fonseca M.P.C. (2011), Residual stress state behaviour under fatigue loading in duplex stainless steel, The Journal of Strain Analysis for Engineering Design, 46(4), 298-303.

19. Roberson R.E. (1951), Vibrations of clamped circular plate carring concentrated mass, Journal Applied Mechanics, 18, 4, 349-352.

20. Rossini N.S., Dassisti M., Benyounis K.Y., Olabi A.G. (2012), Methods of measuring residual stresses in components, Materials and Design, 35, 572-588.

21. Salvati E., Korsunsky A.M. (2017), An analysis of macro- and micro-scale residual stresses of Type I, II and III using FIB-DIC micro-ring-core milling and crystal plasticity FE modelling. International Journal of Plasticity, 98, 123-138.
22. Sangid M.D. (2013), The physics of fatigue crack initiation, International Journal of Fatigue, 57, 58-72.

23. Schajer G.S. (2013), Practical residual stress measurement methods, John Wiley \& Sons Ltd., London.

24. Świć A. (2009), The technology of processing shafts with low stiffness, Publisher of the Lublin University of Technology Lublin (in Polish).

25. Uhl T., Panuszka R. (1983), Determination of resonant frequencies of continuous mechanical systems on the example of a beam and an oscillating plate, Archiwum Budowy Maszyn, 1-2, 111-123 (in Polish).

26. Vardanjani M.J., Ghayour M., Homami R.M. (2016), Analysis of the vibrational stress relief for reducing the residual stresses caused by machining, Experimental Techniques, 40(2), 705-713.

27. Vourna P., Ktena A., Tsakiridis P.E., Hristoforou E. (2015), A novel approach of accurately evaluating residual stress and microstructure of welded electrical steels, NDT \& E International, 71 , 33-42.

28. Wang Q., Liu X., Yan Z., Dong Z., Yan D. (2017), On the mechanism of residual stresses relaxation in welded joints under cyclic loading, International Journal of Fatigue, 105, 43-59.

29. Wesolowski K. (1981), Metallurgy and heat treatment, WNT, Warsaw (in Polish).

30. Zijlstra G., Groen M., Post J., Ocelík V., De Hosson J.Th.M. (2016), On the role of the residual stress state in product manufacturing, Materials \& Design, 105, 375-380.

The research was conducted within S/WZ/1/2015 project and was financed from Ministry of Science and Higher Education funds. 